\title{
NEW RECORS OF MACROFUNGI FROM NGOC LINH MOUNTAIN, QUANG NAM PROVINCE, VIETNAM
}

\author{
Tran Thi Phu ${ }^{1, *}$, Trinh Tam Kiet ${ }^{2}$ \\ ${ }^{1}$ Quang Nam University, Quang Nam, Vietnam \\ ${ }^{2}$ Institute of Microbiology and Biotechnology, VNU, Vietnam
}

Received 7 August 2018, accepted 2 March 2109

\begin{abstract}
Of the total 276 species of class Agaricomycetes collected from Ngoc Linh mountain, Quang Nam province, we identified eight newly recorded species of macrofungi in Vietnam, namely Cymatoderma caperatum, Amanita xanthogala, Chlorophllum brunneum, Chlorophyllum hortense, Hymenopellis megalospora, Psathyrella longipes, Russula cystidiosa, and Serpula lacrymans. The morphologies, anatomical characters were given, additionallysome uses of these fungus species were provided. Among these eight species, two species are edible mushrooms and another three species may be poisonous mushrooms.
\end{abstract}

Keywords: Fungus, new record, Ngoc Linh, Quang Nam.

Citation: Tran Thi Phu, Trinh Tam Kiet, 2019. New recors of macrofungi from the Ngoc Linh mountain, Quang Nam province, Vietnam. Tap chi Sinh hoc, 41(1): 27-33. https://doi.org/10.15625/0866-7160/v41n1.12937.

*Corresponding author email: phutn2014@gmail.com

@2019 Vietnam Academy of Science and Technology (VAST) 


\title{
MộT VÀI LOÀI NẤM MỚI GHI NHẬN CHO KHU HỆ NẤM VIỆT NAM TẠI NÚI NGỌC LINH TỈNH QUẢNG NAM
}

\author{
Trần Thị Phú ${ }^{1, *}$, Trịnh Tam Kiệt ${ }^{2}$ \\ ${ }^{1}$ Trường Đại học Quảng Nam, Quang Nam, Việt Nam \\ ${ }^{2}$ Viện Vi sinh vật và Công nghệ Sinh học, Đại học Quốc gia Hà Nội, Việt Nam
}

Ngày nhận bài 7-8-2018, ngày chấp nhận 2-3-2019

\section{TÓM TÁT}

Trong số 276 loài Ngọc Linh Quảng Nam, có 8 loài là ghi nhậ mới cho khu hệ nấm lớn Việt Nam, đó là: Cymatoderma caperatum, Amanita xanthogala, Chlorophyllum bruneum, Ch.hortense, Hymenopellis megalospora, Psathyrella longipes, Russula cystidiosa và Serpula lacrymans. Một số đặc điểm về hình thái học, sinh thái học, giá thể và công dụng của chúng đã được đề cập, trong đó 2 loài nấm ăn được và 3 loài nấm độc.

Từ khóa: Nấm, ghi nhận mới, Ngọc Linh, Quảng Nam.

*Địa chỉ liên hẹ email: phutn2014@ gmail.com

\section{MỞ ĐẦU}

Núi Ngọc Linh, được che phủ bởi tán rừng nguyên sinh thuộc địa phận của huyện Nam Trà My tỉnh Quảng Nam. Núi Ngọc Linh cao hiểm trở, độ dốc trên $25^{\circ}$, địa hình núi cao, phức tạp, với địa hìnhrừng đa dạng và phong phú. Địa hình rừng núi với sự chia cắt mạnh, nhiều nơi tạo thành các thung lũng nhỏ hẹp, với những độ cao khác nhau. Ngọc Linh là nơi giao thoa của gió mùa Đông Bắc và Tây Nam, với các đặc thù về độ cao, mật độ che phủ, tạo ra vùng khí hậu nhiệt đới và Á nhiệt đới. Với độ ẩm trung bình hàng năm từ 86-87\%, tháng tám cao nhất đạt 94-95\%.

Các số liệu nghiên cứu đã công bố cho thấy cho tới nay có khoảng 3.000 loài nấm đã được xác định, trong đó có gần 2.000 loài nấm lớn. Vùng rừng núi Ngọc Linh, Quảng Nam hầu như chưa được nghiên cứu từ trước tới nay. Trong bài báo nay, chúng tôi trình bày kết quả điều tra thống kê với ghi nhận mới cho khu hệ nấm lớn Việt Nam thuộc lớp Nấm tán Agaricomycetes.

\section{VÂT LIỆ VÀ PHƯƠNG PHÁP NGHIÊN CứU}

Việc thu thập mẫu được tiến hành tại các vùng sinh thái điển hình của huyện Nam Trà My từ năm 2013 đến năm 2017. Các đợt thu mẩu được tiến hành vào các tháng $2,5,7,10$ hằng nằm. Khu vực được chọn điều tra, nghiên cứu có độ cao từ $1.200 \mathrm{~m}$ đến $2.500 \mathrm{~m}$

Các mẫu nấm thu thập trên núi Ngọc Linh, tỉnh Quảng Nam được lưu giữ và bảo quản tại Trường Đại học Quảng Nam và bách thảo nấm thuộc Viện Vi sinh vật và Công nghệ Sinh học, Đại Học Quốc gia Hà Nội. Các phương pháp thu thập, xử lý mẫu nấm và định loại được làm dựa theo Trịnh Tam Kiệt (1981, 2014) và Singer (1986).

\section{KẾT QUẢ VÀ THẢO LUẬN}

Danh lục các loài nấm lớn mới ghi nhận cho khu hệ nấm Việt Nam từ núi Ngọc Linh, Quảng Nam

\section{Bộ Polyporales}

\section{Họ Meruliaceae}

Cymatoderma caperatum (Berk. \& Mont.) (1956) Syn. Stereum caperatum (Berk. 
\& Mont.) Berk., Botanical Journal of the Linnean Society 18: 385 (1881). Số mẫu IMG 3780/82, 3838/39, (3932/33, 3908/10).

\section{Bộ Agaricales \\ Họ Amanitaceae}

Amanita xanthogala Bas. (1969)

Số mẫu IMG 2542/45, 2555, (2631/35, 3373/74, 3504/06, 6744/48, 6771 6825/26).

Chlorophyllum brunneum (Farl. \& Burt) Vellinga (2002). Syn. Lepiota brunnea Farl. \& Burt, Icones Farlowianae 8: pl. 6 (1929); Macrolepiota brunnea (Farl. \& Burt) Wasser, Libri Botanici 9: 82 (1993) Số mẫu IMG 9096/01 (9349/53)

Chlorophyllum hortense (Murrill) Vellinga (2002) Syn. Lepiota hortensis Murrill, North American Flora 10 (1): 59 (1917); Leucoagaricus hortensis (Murrill) Pegler, Kew Bulletin Additional Series 9: 414 (1983). Số mẫu IMG 6706/07, (6712/15, 0310/11).

\section{Họ Physalacriaceae}

Hymenopellis megalospora (Clements) R.H. Petersen (2010).

Syn. Clitocybe megalospora Clem., Botanical Survey of Nebraska 4: 18 (1896); Xerula megalospora (Clem.) Redhead, Ginns \& Shoemaker, Mycotaxon 30: 374 (1987). Số mẫu IMG 5682/83, 5695, (5690/94).

\section{Họ Psathyrellaceae}

Psathyrella longipes (Peck) A.H. Sm. (1941)

Syn: Hypholoma longipes Peck, Bull. Torrey bot. Club 22: 204 (1895). Số mẫu IMG 6063, 6121.

\section{Bộ Russurales}

\section{Họ Russuraceae}

Russula cystidiosa Murrill. (1940)

Syn. Russula integra var. paludosa (Britzelm.) Singer, Z. Pilzk., N.F. 2(1): 7 (1923). Số mẩu IMG 4942/43 6589/90, (6622).

\section{Bộ Boletales \\ Họ Serpulaceae}

\section{Serpula lacrymans (Wulfen) J. Schröt.}

Syn. Merulius lacrymans (Wulfen) Schumach., Enum. pl. (Kjbenhavn) 2: 371 (1803). Số mẫu IMG 4431/4435, (4570/72, 4815/16, 6780/81) (SEM 11).

Như vậy có 4 loài thuộc bộ Agaricales, còn các bộ Polyporales, Rusulales, Boletales mỗi bộ chỉ có 1 loài mới được ghi nhận cho khu hệ nấm lớn Việt Nam.

Đặc điểm hình thái của các loài nấm mới được ghi nhận

Cymatoderma caperatum (Berk. \& Mont.) D.A. Reid Kew Bull. 10 (4): 635 (1956)

Quả thể non dạng phễu, sau trưởng thành phát triển to dần thành dạng phễu nông, có khi lệch áp sát một phần vào giá thể thành dạng quạt, màu vàng nhạt; kích thước ngang $12-18$ rộng 7-10 cm, dày $1,5-2,5 \mathrm{~mm}$; chất bì dai, giòn, mép răng cưa nhẹ, phân thùy nhiều. Mặt mũ có nêp nhăn đến gờ lồi có nhiều nếp. Bào thể nấm ở mặt dưới mũ, có dạng mấu lồi nhỏ, nhiều mụn. Cuống có hình trụ tròn, giữa nhỏ, hai đầu to như chiếc chày giã, có sắc thái xanh lá, kích thước dài 7-12 đường kính 1-2 $\mathrm{cm}$. Hệ sợi 2 sợi gồm sợi nguyên thủy và sợi bện. Chưa tìm thây bào tử và bụi bào tử.

Sinh thái: Hoại sinh trên cây lá kim, gặp ở cuối mùa thu hay đầu mùa xuân. Loài này được tìm thấy đầu tiên ở Mexico, Bắc Mỹ. Ở Việt Nam, loài này được tìm thấy ở độ cao $1500 \mathrm{~m}$, nhiệt độ $15-20^{\circ} \mathrm{C}$, tại núi Ngọc Linh, tỉnh Quảng Nam (hình 1).

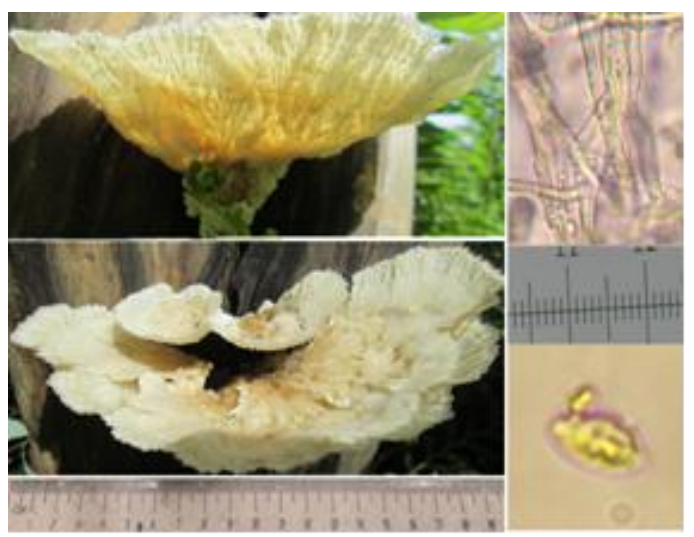

Hình 1. Quả thể, sợi, bào tử vô tính loài Cymatoderma caperatum $(1 \mathrm{div}=1 \mu \mathrm{m})$ 
Amanita xanthogala Bas. Persoonia 5 (3): 490 (1969)

Mũ nấm dạng bán cầu dẹt, kích thước 12 $15 \mathrm{~cm}$ đường kính, phía trên mặt mũ có màu vàng, có nhiều vảy dạng tháp màu vàng đất, trải đều khắp cả mặt mũ và nứt nẻ. Mép mũ màu vàng phủ vảy từ mũ chảy dài đến phiến. Phiến nấm màu vàng cấu trúc gồm các phiến thưa trong đó phiến dài, phiến ngắn xen kẽ. Cuống có màu vàng đất như màu của mũ nấm có vảy dạng gờ dày đặc cả cuống, dạng phình bụng, gần phiến và gốc đường kính $1,2-$ $1,6 \mathrm{~cm}$, giữa có đường kính $1,8-2,3 \mathrm{~cm}$, cuống dài $10-12 \mathrm{~cm}$. Vòng cuống mỏng dạng màng, cách phiến $1-1,5 \mathrm{~cm}$. Gốc cuống có nhiều rễ dài $15-20 \mathrm{~cm}$. Bụi bào tử màu vàng, bào tử có hình bầu dục có giọt dầu. Bào tử có kích thước 4-6 × 7-9 $\mu \mathrm{m}$. Loài này đặc biệt ở chỗ trên mặt mũ có gai trải đều từ chính giữa ra đến mép mũ, cuống có vảy dạng gờ dày đặc, có vòng nâm mỏng dạng màng và có cả rễ nấm.

Sinh thái: Loài này sống cộng sinh trên đất ẩm ướt vào cuối thu. Năm 2015 ở Đông Nam Trung Quốc gặp loài tương tự. Ở Việt Nam loài này mới gặp ở Núi Ngọc Linh, tỉnh Quảng Nam, ở độ cao $1.200 \mathrm{~m}$ trở lên, ẩm độ từ $85-90 \% \mathrm{C}$.

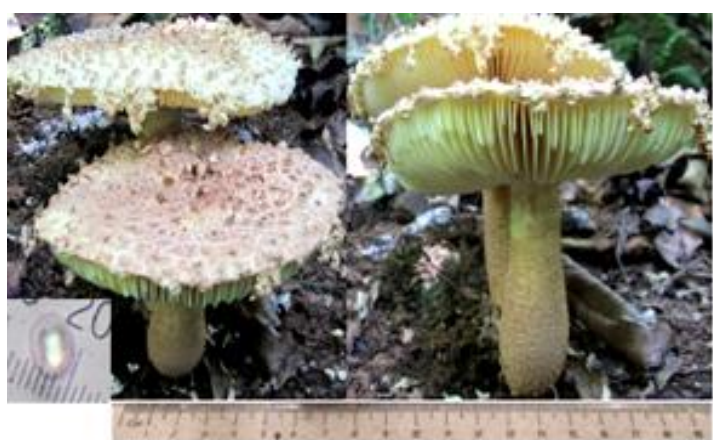

Hình 2. Quả thể và bào tử của loài Amanita xanthogala $(1 \mathrm{div}=1 \mu \mathrm{m})$

Chlorophyllum brunneum (Farl. \& Burt) Vellinga (2002)

Mũ nấm non hình cầu sau phát triển dần thành hình dù tròn, trưởng thành dạng bán cầu dẹt đến thẳng, kích thước $5-15(20) \mathrm{cm}$, phía trên mũ có vảy dạng màng khi tươi màu nâu tím phủ theo dạng vòng tròn, trên chóp mũ sẫm màu hơn, khi khô trở nên đen. Thịt nấm dày màu trắng, phiến nấm đính tự do, rộng, ban đầu màu trẳng, khi về già có màu nâu tím, nâu đỏ. Cuống lúc đầu trẳng sau đó nâu sẫm, dài 5-17(22) cm, đường kính 0,5$0,7(1,0-1,2) \mathrm{cm}$, ở gốc to dạng củ. Vòng nấm màu vàng nâu, dạng màng gồm hai lớp. Bụi bào tử trăng, bào tử có hình elip, kích thước 6-7 × 8-10 $\mu \mathrm{m}$, đảm có kích thước $-9 \times 32-$ $40 \mu \mathrm{m}$. Sinh thái: mọc trong rừng ẩm vào mùa hè, mùa thu, mọc đơn độc hay từng cụm. Phân bố tìm thấy ở Bắc Mỹ (California năm 2015), ở Việt Nam gặp tại núi Ngọc Linh, tỉnh Quảng Nam (hình 3).

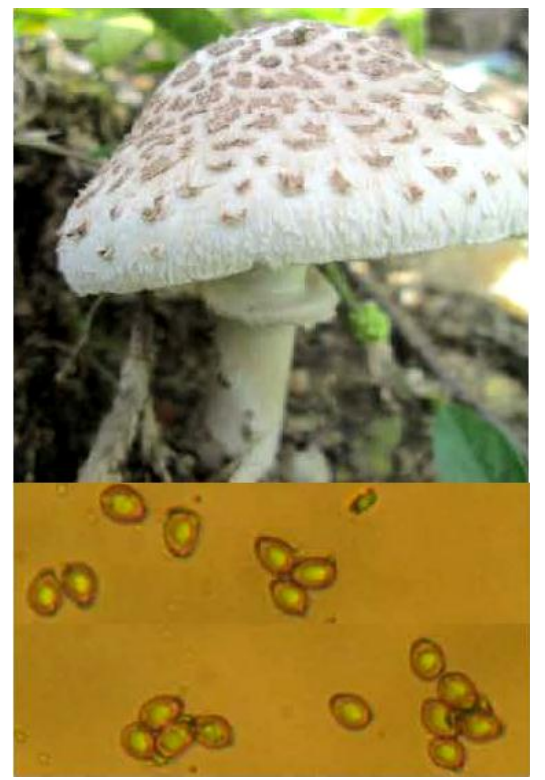

Hình 3. Quả thể và bào tử của loài Chlorophyllum brunneum

Chlorophyllum hortense (Murrill) Vellinga (2002)

Mũ nấm non hình cầu sau phát triển dần thành hình dù tròn, trưởng thành dạng bán cầu dẹt đến thẳng, kích thước $10-15 \mathrm{~cm}$, phía trên mũ có vảy dạng màng màu hồng tím, hồng nâu phủ khắp, trên chóp mũ sẫm màu hơn. Thịt nấm dày màu trắng, phiến nấm đính tự do, rộng, ban đầu màu trăng, khi về già có màu nâu hồng, nâu xanh. Cuông có màu trắng có sắc thái hồng tím, có chiều dài 7-15(20) $\mathrm{cm}$, đường kính $0,4-0,7(1-1,5) \mathrm{cm}$, ở gốc to hơn, dạng trụ, khi chạm tay vào chúng có màu 
nâu hồng, nâu tím. Vòng nấm màu trắng dạng màng gồm hai lớp. Bụi bào tử màu nâu hồng, bào tử có hình elip. Bào tử có kích thước 4 5,5 × 6,5-8 $\mu \mathrm{m}$, đảm có kích thước 7-9 × 30$40 \mu \mathrm{m}$, có 4 tiểu bính. Sinh thái: Loài này, có trong rừng ẩm sau cơn mưa, mọc đơn độc. Phân bố được tìm thấy ở Australia và Bắc Mỹ, năm 2006 tìm thấy ở Trung Quốc, ở Việt Nam mới gặp tại núi Ngọc Linh, tỉnh Quảng Nam, loài nấm này có thể là loài độc (hình 4).

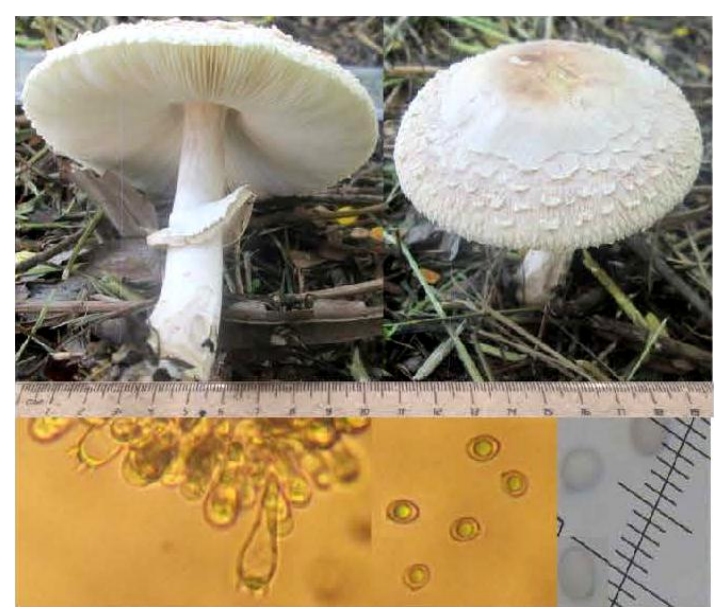

Hình 4. Quả thể, Đảm và bào tử của loài Chlorophyllum hortense $(1 \mathrm{div}=2,5 \mu \mathrm{m})$

Hymenopellis megalospora (Clements) R.H. Petersen (2010)

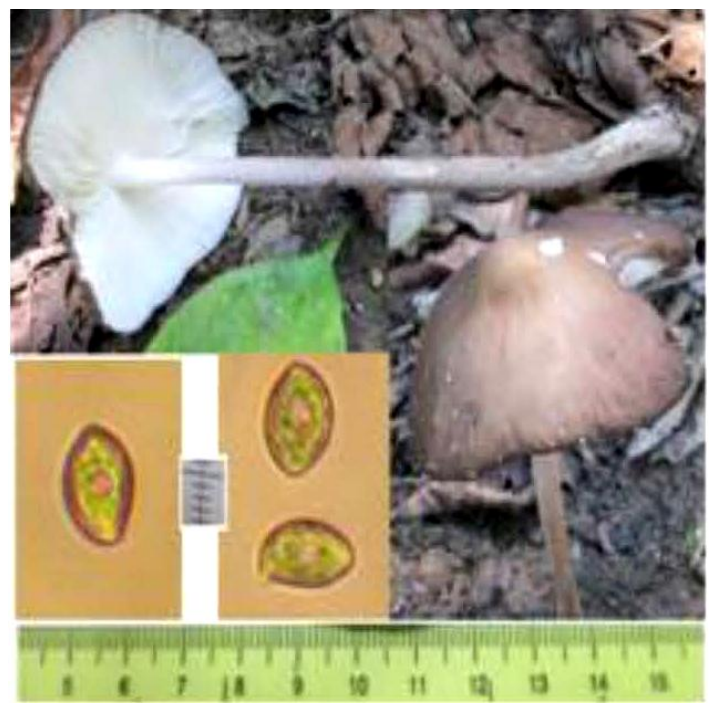

Hình 5. Quả thể, sợi và bào tử của loài Hymenopellis megalospora $(1 \mathrm{div}=2,5 \mu \mathrm{m})$
Quả thể lúc non dạng chuông, khi trưởng thành dạng dù, có khi trải phẳng, kích thước 4-7 cm. Mặt trên màu nâu đất đến màu nâu sữa, hơi nhăn nheo, phiến dày $0,5-1,5 \mathrm{~cm}$, dính, màu trắng. Cuống dạng củ kích thước 0,5-1,5 × 5-16 cm, đặc, có vảy nhỏ, mịn, dày đặc, gốc có rễ giả kéo dài $1-4 \mathrm{~cm}$ trong lòng đất. Bụi bào tử màu trắng, bào tử hình thoi, hơi nhọn 2 đầu, màu vàng, chính giữa có giọt dầu và sắc thái tím, kích thước khá lớn 15-22 $\times 10-14 \mu \mathrm{m}$. Sinh thái: Là loài sống hoại sinh trên đất ẩm, trên rễ cây mục, vào mùa thu. Vị trí địa lý Mexico, ở Việt Nam, loài này được tìm thấy ở độ cao $1.800 \mathrm{~m}$ trên núi Ngọc Linh, tỉnh Quảng Nam, là loài ăn được (hình 5).

\section{Psathyrella longipes (Peck) A.H. Sm.}

Mũ nấm dạng nón, sau tù dần đến dạng trải phẳng, mặt trên màu vàng nhạt có sắc thái hồng, kích thước $2-8 \mathrm{~cm}$, có vảy nhỏ mịn. Thịt nấm màu trắng, phiến tự do, xếp sít nhau, đầu tiên màu trắng có sắc hồng tím, sau đó màu nâu sôcôla. Cuống nấm mảnh, rồng, có màu trắng, dài $5-7 \mathrm{~cm}$, đường kính rộng $0,3-$ $0,8 \mathrm{~cm}$. Bụi bào tử màu nâu, bào tử màu nâu sẫm, kích thước $8-13 \times 6-7 \mu \mathrm{m}$. Sinh thái: Mọc đơn độc hay từng nhóm trên đất khô ngoài bìa rừng vào cuối hè đầu mùa thu, loài này chưa rõ giá trị cụ thể. Ở Việt Nam loài này tìm thấy tại vùng núi Ngọc Linh, tỉnh Quảng Nam (hình 6).

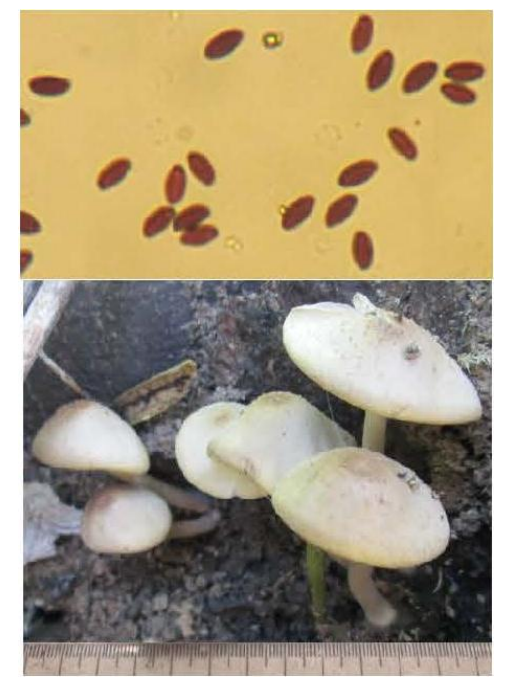

Hình 6. Quả thể và bào tử của loài Psathyrella longipes 


\section{Russula cystidiosa Murrill (1940)}

Mũ nấm khi non hình bán cầu gần như hình chuông, khi già có dạng bán cầu dẹp, trải phẳng, ở giữa lõm xuống, gần mép vểnh lên, đường kính mũ 4-11 cm, có màu nâu đỏ sáng. Mặt mũ láng, không lông, gặp mưa hay thời tiết ẩm sẽ bị nhầy, lớp ngoài rất dễ lột ra, tự bong ra. Thịt nâm có màu trắng, hơi phớt hồng, xốp, giòn, dễ gãy, phiến nấm màu trắng, hơ đính rộng. Cuống có màu trắng, sắc hồng, dài 2-7 cm, dày $0,5-1,5 \mathrm{~cm}$, hình trụ hơi tròn ở bụng. Bụi bào tử màu kem. Bào tử hình cầu, có nhiều gai, màu vàng, có giọt dầu, kích thước 6-10 × 7-12 $\mu \mathrm{m}$. Sinh thái: Hoại sinh ở cỏ nơi đất ẩm, xuất hiện vào cuối thu. Loài này gặp ở Bắc Mỹ, là loài nấm ăn được. Ở Việt Nam, gặp ở Ngọc Linh, tỉnh Quảng Nam những ngày đâu mùa mưa (hình 7 ).

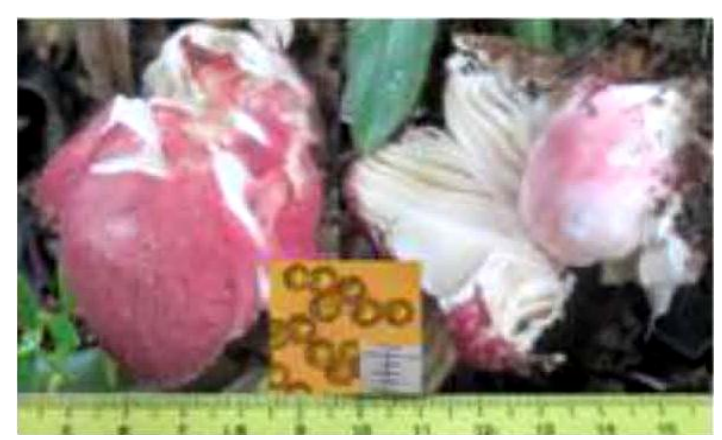

Hình 7. Quả thể và bào tử của loài Russula cystidiosa $(1 \mathrm{div}=2,5 \mu \mathrm{m})$

\section{Serpula lacrymans (Wulfen) J. Schröt.}

Quả thể trải phẳng, dạng sò hay thay đổi hình dạng tùy theo vị trí hoại sinh. Kích thước khá lớn 5-10 × 12-25 cm có khi lớn hơn, mỏng $0,3-0,7 \mathrm{~cm}$, (tùy theo thời gian phá hủy của nấm), có màu vàng đậm, Quả thể tươi và khô đều mềm màu vàng tươi, đến màu nâu sẫm. Mặt trên hơi nhăn, mặt dưới lỗ hình đa giác không đều. Bụi bào tử dày đặc, phát tán bám vào giá thể có màu vàng. Bào tử có hình elip tròn đầu, có giọt dầu tương đối lớn, kích thước bào tử 2-3 × 4-5 $\mu \mathrm{m}$. Sinh thái: Loài này sống ở nơi ẩm tối dưới gốc tre già tại tán rừng $\mathrm{Ngọc} \mathrm{Linh,} \mathrm{tỉnh} \mathrm{Quảng} \mathrm{Nam,} \mathrm{là} \mathrm{loài} \mathrm{nấm}$ gây mục nâu, phá hoại gỗ rất nhanh, ở những nơi ẩm thấp, tối, nhiệt độ $5-20^{\circ} \mathrm{C}$ và ẩm độ $80 \%$ thuận lợi cho loài nấm này phát triển.
Loài nấm này cũng là loài gây hại gỗ nguy hiểm ở các vùng châu Âu. Loài này cũng gặp ở các vùng núi cao dãy Hymalaya, bắc California. Ở Việt Nam, loài này gặp ở Ngọc Linh, tỉnh Quảng Nam dưới gốc tre già tại tán rừng rậm ẩm và tối (hình 8 ).

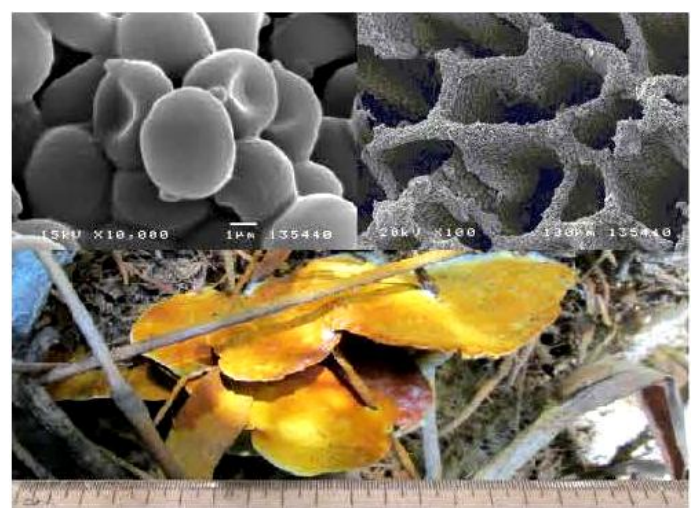

Hình 8. Quả thể, ống và bào tử của loài Serpula lacrymans

\section{KẾT LUẬN}

Ghi nhận mới 8 loài nấm lớn cho khu hệ nấm Việt Nam từ Ngọc Linh, bao gồm Cymatoderma caperatum, Amanita xanthogala, Chlorophllum brunneum, Chlorophyllum hortense, Hymenopellis megalospora, Psathyrella longipes, Russula cystidiosa, Serpula lacrymans của lớp Agaricomycetes chứng tỏ sự đa dạng sinh học cao của khu hệ nấm của Việt Nam.

Trong 8 loài nấm mới ghi nhận, có 2 loài nấm ăn được và 3 loài có thể là nấm độc.

\section{TÀI LIẾU THAM KHẢO}

Rodham E. T., Cristina R. C., Karen W. H., Jozsef G., Linas V. K., Benjamin E. W., David A., 2015. Nomenclatural changes in Amanita. II, Amanitaceae, 2: 1-6.

Else C. V., 2003. Chlorophyllum and Macrolepiota (Agaricaceae) in Auscaceae, Bontany pp 361-370.

Else C. V., 2008. Chlorophyllum, pp. 1-6.

Trịnh Tam Kiệt, 2011. Nấm lớn ở Việt Nam, tập 1. Nxb. KHTN\&CN.

Trịnh Tam Kiệt, 2013. Nấm lớn ở Việt Nam, tập 3. Nxb. KHTN\&CN. 
Trịnh Tam Kiệt, 2014. Danh lục Nấm lớn của Việt Nam. Nxb. Đại học Quốc gia Hà Nội.
Singer R., 1986. The Agaricales in modern taxonomy. Koeltz Scientific books D6240 Koenigstein Federal Republic, Germany. 